\title{
Are differences in population prevalence of alcohol's harm to others related to survey administration mode?
}

\author{
Erica Sundin ${ }^{1,2}$, Jonas Landberg ${ }^{1,2}$, Maria Rosaria Galanti ${ }^{3,4}$, Robin Room ${ }^{5,6}$, Mats Ramstedt ${ }^{1,2}$ \\ ${ }^{1}$ Department of Clinical Neuroscience, Centre for Psychiatry Research, Karolinska Institute, Stockholm, Sweden \\ ${ }^{2}$ The Swedish Council for Information on Alcohol and Other Drugs, Stockholm, Sweden \\ ${ }^{3}$ Department of Public Health Sciences, Karolinska Institute, Stockholm, Sweden \\ ${ }^{4}$ Centre for Epidemiology and Community Medicine, Stockholm County Council, Stockholm, Sweden \\ ${ }^{5}$ Centre for Alcohol Policy Research, La Trobe University, Melbourne, Australia \\ ${ }^{6}$ Centre for Social Research on Alcohol and Drugs, Stockholm University, Stockholm, Sweden
}

Running head: Survey mode and alcohol's harm to others

Erica Sundin BMedSc, PhD student, Jonas Landberg PhD, Assistant Professor, Maria Rosaria Galanti PhD, Adjunct Professor, Robin Room PhD, Professor, Mats Ramstedt PhD, Associate Professor. Correspondence to Ms Erica Sundin, The Swedish Council for Information on Alcohol and Other, Box 70412, 10725 Stockholm, Sweden. Tel: +4672 37143 32; E-mail: erica.sundin@ki.se

This is the author manuscript accepted for publication and has undergone full peer review but has not been through the copyediting, typesetting, pagination and proofreading process, which may lead to differences between this version and the Version of Record. Please cite this article as doi: $10.1111 /$ dar.12550

This article is protected by copyright. All rights reserved. 


\begin{abstract}
Introduction and Aims: This study assessed the comparability of estimates of alcohol's harm to others across different administration modes in Swedish general population surveys. Harm was categorised as harm from strangers' drinking and harm from heavy drinkers known to the respondent. Design and Methods: Three surveys were conducted in 2011/2012 ( $n=6841$ ) including identical questions. One was based on self-administered postal or web questionnaires and two were based on computer-assisted telephone interviews of which one included a more ambitious procedure in terms of monetary incentives to the respondents. Pearson chi-square tests were used to compare differences in the prevalence of harm. To estimate potential effects of survey mode, the samples were pooled and multivariate Poisson regression models with mode as explanatory variable were used, adjusting for socio-demographic and behavioural factors. Results: Respondents in the two computer-assisted telephone interviews were more likely to report harm from strangers' drinking compared to respondents in the self-administered postal or web questionnaires. However, no significant differences were found between survey modes concerning reports of harm from known people's drinking. Discussion and Conclusions: A survey mode based on interviews seems to facilitate reports of harm from strangers' drinking. This does not apply to reports of harm from known people's drinking. Therefore, the comparability of estimates of alcohol's harm to others between survey modes depends on the type of harm being studied.
\end{abstract}

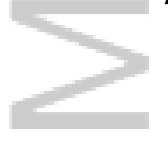

Key words: alcohol's harm to others, general population survey, administration mode, Sweden, prevalence

This article is protected by copyright. All rights reserved. 


\section{Introduction}

Suffering harm from other people's drinking is a common experience in the general population [1-9]. Harm ranges from noisy drunken neighbours to fatal accidents due to drunk driving and has been estimated to account for societal costs similar to those related to direct consequences for the individual drinkers [4].

A frequent approach to study these problems is through cross-sectional surveys [10] in which respondents are asked to report adverse experiences from others' drinking, often referred to the last 12 months. Findings from such studies are often used for international comparisons of population prevalences of negative consequences of others' drinking $[5,6,11]$. A limitation of these comparative studies is that the surveys often employ different modes of data collection, jeopardising the comparability. At the same time, there is a lack of studies addressing the effect of survey administration mode on the estimates of alcohol's harm to others.

A review of general health surveys by Bowling [12] found that willingness to reveal socially undesirable information is higher in self-administered questionnaires (SAQ) (e.g. postal and web questionnaires) than in interviewer-administered questionnaires (IAQ) (e.g. telephone and face-toface interviews). This conclusion was also drawn in a recent review of alcohol surveys by Johnson [13], who found that higher rates of alcohol use were generally obtained in SAQs than in IAQs. These studies support the notion that the extent to which an alcohol-related problem is captured in a specific survey mode depends on the respondent's perception of how socially undesirable the problem is. Features casting a negative light on the respondent, for instance changing personality when drinking, tend to be more commonly reported in SAQs, whereas taking steps to reduce or control own drinking tend to be more reported in IAQs [14].

It is not evident that self-reported harm caused by others' drinking would follow these patterns, since reporting such problems might be less sensitive than reporting one's own socially undesirable behaviour. As harm from others' drinking may be caused by people who are in different relationships to the respondent $[15,16]$, the survey mode's effect may also depend on the type of harm being reported. For example, it is possible that harm from drinking inflicted by someone close to the respondent is perceived as more sensitive information than harm inflicted by unknown persons.

This article is protected by copyright. All rights reserved. 
Results may also vary across survey modes since these may appeal to population subgroups differently, leading to differential non-response. For instance, older individuals seem to prefer IAQ modes over SAQ modes [17] and since they are less likely to be harmed by others' drinking [1,3,5-7], the overall results may be biased downwards in comparison to SAQ studies. Thus, when comparing modes of data collection, it is also important to take into account the socio-demographic characteristics of the samples.

The aim of this study is to assess the comparability of survey estimates of alcohol's harms to others across different administration modes employing identical questions. More specifically, we will investigate if self-reported estimated prevalence of harm from other's drinking differs between survey modes after adjustment for participant characteristics. The analyses will be conducted separately for two different types of harm: harm from strangers' drinking and harm from heavy drinkers close to the respondent. We hypothesised that reporting harm from known persons' drinking would be affected by social desirability, reflected by a lower prevalence in telephone interviews compared to SAQ.

\section{Methods}

\section{Survey administration modes}

Data were obtained from a Swedish study designed to compare self-reported responses to identical items in cross-sectional surveys with different administration modes: (i) self-administered questionnaires (SAQ-post/web) where the participants could choose between answering a postal or a web version of the questionnaire; (ii) standardised computer-assisted telephone interviews (CATIstandard); and (iii) computer-assisted telephone interviews performed by trained interviewers with a more ambitious procedure (CATI-ambitious). This latter procedure involved informing respondents about the interview in advance with a letter and offering a monetary incentive of SEK 100 (about $€$ 11) for participation. Non-Swedish-speaking respondents were offered help of an interpreter. In addition, regular consultation meetings took place between interviewers and survey supervisors to discuss interpretations of the questions. An information letter and a monetary incentive were also used in the SAQ-post/web mode, where a larger proportion of the respondents chose to answer the postal questionnaire (83\%) than the web version (17\%). 
Random digit dialling based on home and cell phone numbers with the last birthday selection method was used in the CATI-standard, while respondents in the other two modes were drawn from the Swedish Population Register, which includes all individuals registered as residing in Sweden. The response rates in the three surveys were calculated as the proportion participating to the total number of individuals in the respective sample, corresponding to $42 \%$ (CATI-standard), 62\% (SAQpost/web) and $67 \%$ (CATI-ambitious). The study was authorised by the Central Ethical Review Board in Stockholm (registration number: 2011/1453-31/5).

The surveys were conducted in 2011-2012 and include random samples of individuals aged 17-84 years (born 1927-1994). The final samples were weighted in order to resemble the correct distribution of gender and age in the source population and in order to achieve comparable samples between modes. Details about sampling and methods for data collection as well as response rates and descriptive information are presented in Table 1. Even though the samples were weighted, participant characteristics differed to some degree between the survey modes. Differences were in particular found between the SAQ-post/web and the CATI-standard mode, where the distribution of educational level, unemployment and birth origin differed significantly (Table 1). The distribution of respondents living with children and self-reported binge drinking frequency differed significantly between all survey modes, whereas gender, age and partner status did not differ between any of the modes.

- Table 1 about here -

\section{Measurements}

Two dichotomised dependent variables were used: reports of harm from strangers' drinking and harm from heavy drinkers among the respondent's acquaintances, based on questions deriving from the World Health Organization-ThaiHealth project [18]. Participants were asked 'In the last 12 months, has there been someone in your life that you consider to have been drinking too much alcohol (it can be on a regular basis or occasionally)? Examples of such people are: relatives, expartner, friends or co-workers.' Second, to measure whether this had negatively affected respondents, they were asked 'Did that person's/those persons' drinking affect you negatively in

This article is protected by copyright. All rights reserved. 
some way during the last 12 months?'. Respondents who answered positively on both items were categorised as having been harmed by known people's drinking. Harm inflicted by unknown people's drinking was investigated with the question 'Have you at any time, during the last 12 months, been negatively affected by the drinking of a stranger or people you do not know very well? (e.g. been unable to sleep, felt insulted or afraid, been harmed or injured, or had property destroyed.)' Respondents who responded affirmatively were categorised as having been harmed by strangers' drinking. Missing answers to either of these questions were considered as missing information in the corresponding variable.

Socio-demographic variables included: gender (male; female); age categorised in roughly 10-year categories (17-24; 25-34; 35-44; 45-54; 55-64; 65-74; 75-84); Swedish origin (yes; no); educational level (elementary school; high school; university); unemployment or on long-term sick leave (yes; no); partner status (living with a partner; not living with a partner); and presence of children in the household (living with a child; not living with a child).

The respondent's binge drinking was derived from a question about how often during the last 12 months the respondent drank an amount of alcohol corresponding to approximately six units of alcohol - equivalent to 1 bottle of wine ( 75 centilitres), five shot glasses of spirits, 4 cans of beer, 4 cans of cider or alcopops or 6 cans of 'folkbeer' (beer containing 2.8-3.5\% alcohol), with nine response alternatives ranging from 'never' to 'more or less every day'. The answers were categorised as never (including abstainers), a few times a year, 1-3 times a month, and once a week or more often.

\section{Statistical analyses}

Pearson chi-square was used to compare the crude prevalence of the two types of harm across survey modes (Figure 1). We explored the potential effect of survey mode on the estimated prevalence of harm with a pooled sample with survey mode as explanatory variable through Poisson regression models with a robust error variance [19], yielding an estimate of Relative Risks (RR) with 95\% confidence intervals ( $\mathrm{Cl})$. As a final step we also included socio-demographic and behavioural characteristics of the participants in the models in order to correct for their different distribution across the survey modes (Table 2). Since the two dependent variables had a weak positive correlation according to Spearman's Rho (coefficient $=0.279, P=0.01$ ), bivariate probit models that 
allows for correlated error terms between the two indicators [20] were performed as a sensitivity analysis in order to assess the suitability of the Poisson regression analyses while estimating the mode effects. The two dependent variables as well as the correlates were included in the model. Sensitivity analyses were performed to further test whether variations in non-response rates among the surveys could explain potential differences between modes by assuming that late respondents are more similar to non-respondents [21]. Therefore, we measured whether the prevalence of the two types of harm varied between early and late respondents in each mode. To this end, we used Pearson chi-square to test for differences between proportions.

In SAQ-post/web early respondents included participants who responded to the initial questionnaire and those who responded after the first reminder, and late respondents included those who responded after the second reminder. In CATI-standard and CATI-ambitious modes early respondents were participants who responded after 1-11 contact attempts and late respondents included those who responded after 12 or more contact attempts. The distribution of early and late respondents was as follows: 82.3 and $17.7 \%$ in the SAQ-post/web; 80.2 and $19.8 \%$ in the CATI-standard; and 73.4 and $26.6 \%$ in the CATI-ambitious.

\section{Results}

\section{Prevalence of self-reported harm from others' drinking according to survey mode}

A significantly higher prevalence of harm from strangers' drinking was found in the CATI-ambitious (16.2\%) compared to the CATI-standard (13\%) and the SAQ-post/web mode (11.5\%), whereas the prevalence did not differ significantly between the SAQ-post/web and CATI-standard modes (Figure 1). Regarding harm from drinkers known to the respondent, the highest prevalence, $17.2 \%$, was found in the CATI-ambitious, followed by the SAQ-post/web (16.3\%) and the CATI-standard (15.1\%) modes. The differences between the modes were not statistically significant.

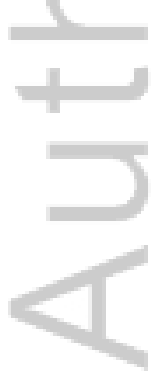

- Figure 1 about here -

This article is protected by copyright. All rights reserved. 


\section{Association of survey mode with self-reported harm from others' drinking}

Findings from the model adjusting for sample characteristics showed that answering in the CATIstandard mode increased the likelihood of reporting harm from strangers' drinking by $28 \%(R R=1.28)$ compared to being in the SAQ-post/web mode (Table 2); answering in the CATI-ambitious mode increased the likelihood even more -- by $52 \%(R R=1.52)$. Conversely, no significant differences between modes were found for reporting harm from known people's drinking.

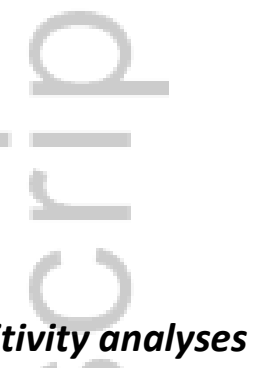

\section{Sensitivity analyses}

A sensitivity analysis using a bivariate probit model showed results in line with those presented in Table 2 (analyses not shown, available from the first author on request).

Sensitivity analyses using Pearson chi-square tests showed no statistically significant difference in prevalence of the two types of reported harm between groups of early and late respondents between any of the modes (analyses not shown, available from the first author on request).

\section{Discussion}

This study addressed the comparability of different survey administration modes with respect to reported harm from strangers' and known people's drinking. A significantly higher crude prevalence of harm from strangers' drinking was found in the CATI-ambitious mode (16.2\%) compared to the SAQ-post/web mode (11.5\%), whereas the prevalence did not differ significantly between the SAQpost/web and CATI-standard modes (11.5 vs. 13\%). A lower level of reported harm from strangers' drinking in the SAQ-post/web mode remained after controlling for differences in sample characteristics. Reporting harm from strangers' drinking seems to be little affected by social desirability bias, since the respondents in the two interview modes were more likely to report harm than respondents in the SAQ-post/web mode. On the other hand, these differences may also be an effect of increased acquiescence or 'yes-saying' bias in the interviews. In fact, participants might perceive that answering affirmatively to a question may more likely please the interviewer than a negative response.

This article is protected by copyright. All rights reserved. 
These findings could also indicate that the interview setting, where the presence of an interviewer facilitates recall and clarification of questions [12], provides higher sensitivity than SAQ when assessing harm from strangers' drinking. In these surveys, harm due to unknown people's drinking was rather broadly defined and included a variety of examples that could be confusing for the respondent if left without guidance.

As to estimates of harm from known people's drinking, the crude prevalence did not differ significantly between modes and ranged from $15.1 \%$ in the CATI-standard, $16.3 \%$ in the SAQpost/web and $17.2 \%$ in the CATI-ambitious. This finding remained when controlling for differences in sample characteristics. Therefore, the hypothesis that harm from known people's drinking would be underreported in the interview modes was not supported in this study. On the other hand, for this specific type of experience the interview setting did not convey a sensitivity advantage compared to the questionnaire-based mode, as it did for harm caused by strangers. Thus it is still possible that reports from participants in the interview settings may have been affected by social desirability to some extent. The question on harm from known people's drinking may not be affected by the above mentioned "acquiescence bias" due to the higher emotional load of such question. Hence, the need to please the interviewer would be a minor concern in this case.

Cognitive processes may also explain the lower gap in sensitivity between the different modes when assessing harm from people close to the respondents. In fact, the cognitive work needed to answer the questions related to the two types of harm was probably different. Compared to harm from strangers' drinking, harm from known people's drinking was more precisely defined in the surveys. The respondents were first asked if there was someone in their life who drinks too much and then they were asked if they had been negatively affected by that person's drinking. Focusing on a specific person and his/her behaviour may make it easier for the respondent to recall such events, regardless of mode.

There could be a concern that the prevalence of harm due to known people's drinking may have been underestimated in the CATI-standard mode owing to a significantly lower proportion of binge drinking participants, who are often found to be more negatively affected by others' drinking [1,3,5$7,22]$. However, no such pattern was found concerning harm from strangers' drinking, although the explanation could also be applicable to these situations.

This article is protected by copyright. All rights reserved. 
To our knowledge, this is the first methodological study directly addressing mode effects in estimating harm from others' drinking, a growing research area not least in terms of international comparisons based on general population surveys. The major strength of this study is that it was explicitly designed to assess survey mode effects with identical survey questions. To the limitations belong differences in non-response rates between the studies and the subsequent difficulty to distinguish between mode effects and implications of non-response. However, the results from the sensitivity analyses suggested that variations in non-response would not explain the survey mode effects.

Further research is warranted to explain the reasons of administration mode effects found in this study. In particular, qualitative/narrative information may be required as a complement to quantitative assessments in order to explore the participant's perception of the cognitive and emotional burden posed by this type of questions. This kind of research can also help clarifying possible social differences in perception and reports of harm, the direction of which is to date just a matter of speculations based on untested assumptions.

\section{Conclusions}

The comparability of estimates of alcohol's harm to others between survey modes depends on the type of harm being studied, with a stronger uncertainty for comparison of harm from strangers' drinking than for harm from known people's drinking. These findings are important to consider when comparing estimates of harm from other's drinking across survey modes.

\section{Acknowledgements}

Revised from a paper presented at the $42 \mathrm{nd}$ annual alcohol epidemiology symposium of the Kettil Bruun Society. Stockholm, Sweden, 30 May to 3 June 2016. Thanks to the project group, led by associate professor Anders Tengström, involved in the data collection: Klara Hermansson, Josefin Norman and Ingvar Rosendahl.

This article is protected by copyright. All rights reserved. 


\section{References}

[1] Fillmore KM. The social victims of drinking. Br J Addict 1985;80:307-14.

[2] Hradilova Selin K, editor. Svenska dryckesvanor och deras konsekvenser i början av det nya millenniet [Swedish drinking habits and their consequences in the beginning of the new millennium]. Stockholm: The Centre for Social Research on Alcohol and Drugs (SoRAD). Report;2004:20.

[3] Huhtanen P, Tigerstedt C. Women and young adults suffer most from other people's drinking. Drug Alcohol Rev 2012;31:841-6.

[4] Laslett A-M, Catalano PT, Chikritzhs T, et al. The Range and Magnitude of Alcohol's Harm to Others. Fitzroy, Victoria: AER Centre for Alcohol Policy Research, Turning Point Alcohol and Drug Centre, Eastern Health, 2010.

[5] Moan IS, Storvoll EE, Sundin E, et al. Experienced harm from other people's drinking: A comparison of northern European countries. Subst Abuse 2015;9(Suppl 2):45-57.

[6] Ramstedt M, Sundin E, Moan IS, et al. Harm experienced from the heavy drinking of family and friends in the general population: A comparative study of six northern European countries. Subst Abuse 2015;9(Suppl 2):107-18.

[7] Rossow I, Hauge R. Who pays for the drinking? Characteristics of the extent and distribution of social harms from others' drinking. Addiction 2004;99:1094-102.

[8] Seid AK, Grittner U, Greenfield TK, Bloomfield K. To cause harm and to be harmed by others: New perspectives on alcohol's harms to others. Subst Abuse 2015;9(Suppl 2):13-22.

[9] Laslett A-M, Room R, Ferris J, Wilkinson C, Livingston M, Mugavin J. Surveying the range and magnitude of alcohol's harm to others in Australia. Addiction 2011;106:1603-11.

[10] Rossow I. How well do survey studies capture alcohol's harm to others? Subst Abuse 2015;9(Suppl 2):99-106.

[11] Callinan S, Laslett AM, Rekve D, Room R, Waleewong O, Benegal V, et al. Alcohol's harm to others: An international collaborative project. Int J Alcohol Drug Res 2016;5:24-32.

[12] Bowling A. Mode of questionnaire administration can have serious effects on data quality. Public Health (Oxf) 2005;27:281-91.

[13] Johnson T. Sources of error in substance use prevalence surveys. Int Sch Res Notices 2014:1-21.

[14] Parks KA, Pardi AM, Bradizza CM. Collecting data on alcohol use and alcohol-related victimization: a comparison of telephone and Web-based survey methods. J Stud Alcohol 2006;67:318-23.

[15] Room R, Ferris J, Laslett AM, Livingston M, Mugavin J, Wilkinson C. The drinker's effect on the social environment: a conceptual framework for studying alcohol's harm to others. Int J Environ Res Public Health 2010;7:1855-71.

[16] Storvoll EE, Moan IS, Lund IO. Negative consequences of other people's drinking: Prevalence, perpetrators and locations. Drug Alcohol Rev 2016;35:755-62.

[17] Smyth JD, Olson K, Millar MM. Identifying predictors of survey mode preference. Soc Sci Res 2014;48:135-44.

This article is protected by copyright. All rights reserved. 
[18] Rekve D, Laslett A-M, Room R, Thamarangsi T, Waleewong O. The Harm to Others from Drinking: A WHO/ThaiHealth International Collaborative Research Project. Melbourne: Centre for Alcohol Policy Research, La Trobe University and Bangkok: Thai Health Promotion Foundation, 2012.

[19] Zou G. A modified Poisson regression approach to prospective studies with binary data. Am J Epidemiol 2004;159:702-6.

[20] Jones A. Applied econometrics for health economists: a practical guide, 2nd edn. Oxford and Seattle: Radcliffe Publishing and Office of Health Economics OHE, 2007.

[21] Rogelberg S.G, Luong A. Nonresponse to mailed surveys: A review and guide. Curr Dir Psychol Sci 1998;7:60-5.

[22] Laslett A-M, Callinan S, Mugavin J, Jiang H, Livingston M, Room R. Beyond the Drinker: Longitudinal Patterns in Alcohol's Harm to Others. Canberra: Foundation for Alcohol Research \& Education, 2015.

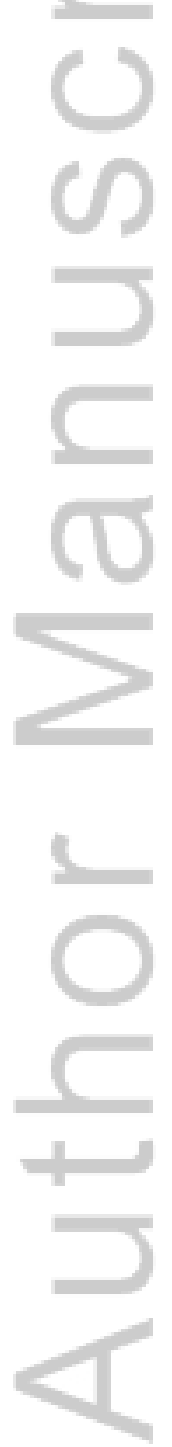

This article is protected by copyright. All rights reserved. 
Table 1. Survey and sample characteristics according to administration mode.

\begin{tabular}{|c|c|c|c|c|}
\hline & SAQ-post/web & CATI-standard & CATI-ambitious & \\
\hline Data collection period & November 2011 - March 2012 & $\begin{array}{l}\text { November } 2011 \text { - December } \\
2011\end{array}$ & November 2011 - April 2012 & \\
\hline Sample & Random sample from SPAR ${ }^{a}$ & $\begin{array}{l}\text { Random digit dialling sample } \\
\text { (home and cell phone numbers) }\end{array}$ & Random sample from SPAR ${ }^{a}$ & \\
\hline Extra effort to reach respondents & Introductory letter, voucher & - & $\begin{array}{l}\text { Introductory letter, voucher, } \\
\text { trained interviewers }\end{array}$ & \\
\hline Contact attempts, \% (n) & Up to 2 reminder letters & Up to 30 calls & Up to 25 calls & \\
\hline Early respondents & $82.3(2050)$ & $80.2(2409)$ & $73.4(987)$ & \\
\hline Late respondents & $17.7(442)$ & $19.8(596)$ & $26.6(357)$ & \\
\hline Response rate (\%) & 62 & 42 & 67 & \\
\hline Number of participants & 2,492 & 3,005 & 1,344 & \\
\hline \multicolumn{4}{|c|}{ Characteristics of the samples (weighted data) } & Significant mode differences ${ }^{b}$ \\
\hline Gender, \% (n) & & & & ns \\
\hline Female & $50.0(1245)$ & $50.0(1502)$ & $50.0(672)$ & \\
\hline Male & $50.0(1247)$ & $50.0(1503)$ & $50.0(672)$ & \\
\hline Age, $\%(n)$ & & & & ns \\
\hline $17-24$ & $13.8(345)$ & $13.8(416)$ & $13.8(186)$ & \\
\hline $25-34$ & $15.9(396)$ & $15.9(477)$ & $15.8(213)$ & \\
\hline $35-44$ & $17.1(426)$ & $17.1(514)$ & $17.1(230)$ & \\
\hline $45-54$ & $16.8(418)$ & $16.8(504)$ & $16.8(226)$ & \\
\hline $55-64$ & $15.8(393)$ & $15.8(474)$ & $15.8(212)$ & \\
\hline $65-74$ & $13.2(329)$ & $13.2(396)$ & $13.2(177)$ & \\
\hline $75-84$ & $7.4(185)$ & $7.4(223)$ & $7.4(100)$ & \\
\hline Swedish origin ${ }^{c}, \%(n)$ & & & & $A$ vs $B ; B$ vs $C$ \\
\hline Yes & $84.0(2087)$ & $90.4(2716)$ & 85.9 (1153) & \\
\hline No & $16.0(398)$ & $9.6(288)$ & $14.1(190)$ & \\
\hline Education $^{d}, \%(n)$ & & & & $A$ vs $B$ \\
\hline Elementary school & 22.7 (529) & $18.2(539)$ & $20.6(261)$ & \\
\hline High school/ gymnasium & $37.3(869)$ & $42.7(1263)$ & $41.4(524)$ & \\
\hline University & $40.0(931)$ & 39.1 (1159) & $38.0(482)$ & \\
\hline Unemployed/long-term sick & & & & $A$ vs $B$ \\
\hline
\end{tabular}

This article is protected by copyright. All rights reserved. 


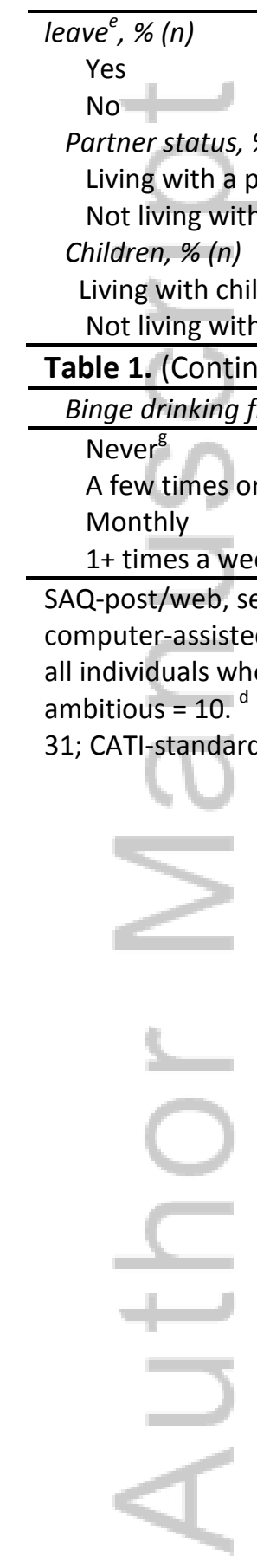

$\begin{array}{lll}7.7(187) & 6.1(181) & 6.6(88) \\ 92.3(2233) & 93.9(2798) & 93.4(1245)\end{array}$

ns

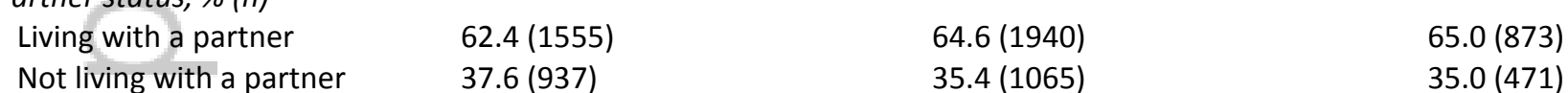

$\%(n)$

$31.8(792) \quad 28.8(865) \quad 36.2(486)$

$63.8(858)$

$A$ vs $B ; A$ vs $C ; B$ vs $C$

$68.2(1700)$

$71.2(2140)$

$A$ vs $B ; A$ vs $C$; $B$ vs $C$

$\begin{array}{lll}32.5(801) & 54.4(1591) & 43.0(577) \\ 32.6(803) & 24.3(710) & 28.5(383) \\ 21.5(530) & 14.8(434) & 21.2(284) \\ 13.4(330) & 6.5(189) & 7.3(98)\end{array}$

6.5 (189)

$21.2(284)$

computer-assisted telephone interviews with a more ambitious procedure; ns, not significant; vs, versus. ${ }^{\text {a }}$ Statens personadress register (SPAR) address list which includes all individuals who are registered as residents in Sweden. ${ }^{\mathrm{b}}$ Pearson chi-square test of significance $(P<0.05)$. ${ }^{\mathrm{C}} \mathrm{Missing}$ cases; SAQ-post $/$ web $=72 ; \mathrm{CATI}$-standard $=26$; CATIambitious $=10$. ${ }^{\mathrm{d}}$ Missing cases and cases of unspecified education; SAQ-post/web = 27, 158; CATI-standard = 7, 42; CATI-ambitious = 3, 75. ${ }^{\mathrm{e}}$ Missing cases; SAQ-post/web =

31; CATI-standard $=84$; CATI-ambitious $=26 .{ }^{f}$ Missing cases; SAQ-post $/$ web $=31 ;$ CATI-standard $=84 ;$ CATI-ambitious $=2 .{ }^{\mathrm{g}}$ Including non-drinkers.

This article is protected by copyright. All rights reserved. 


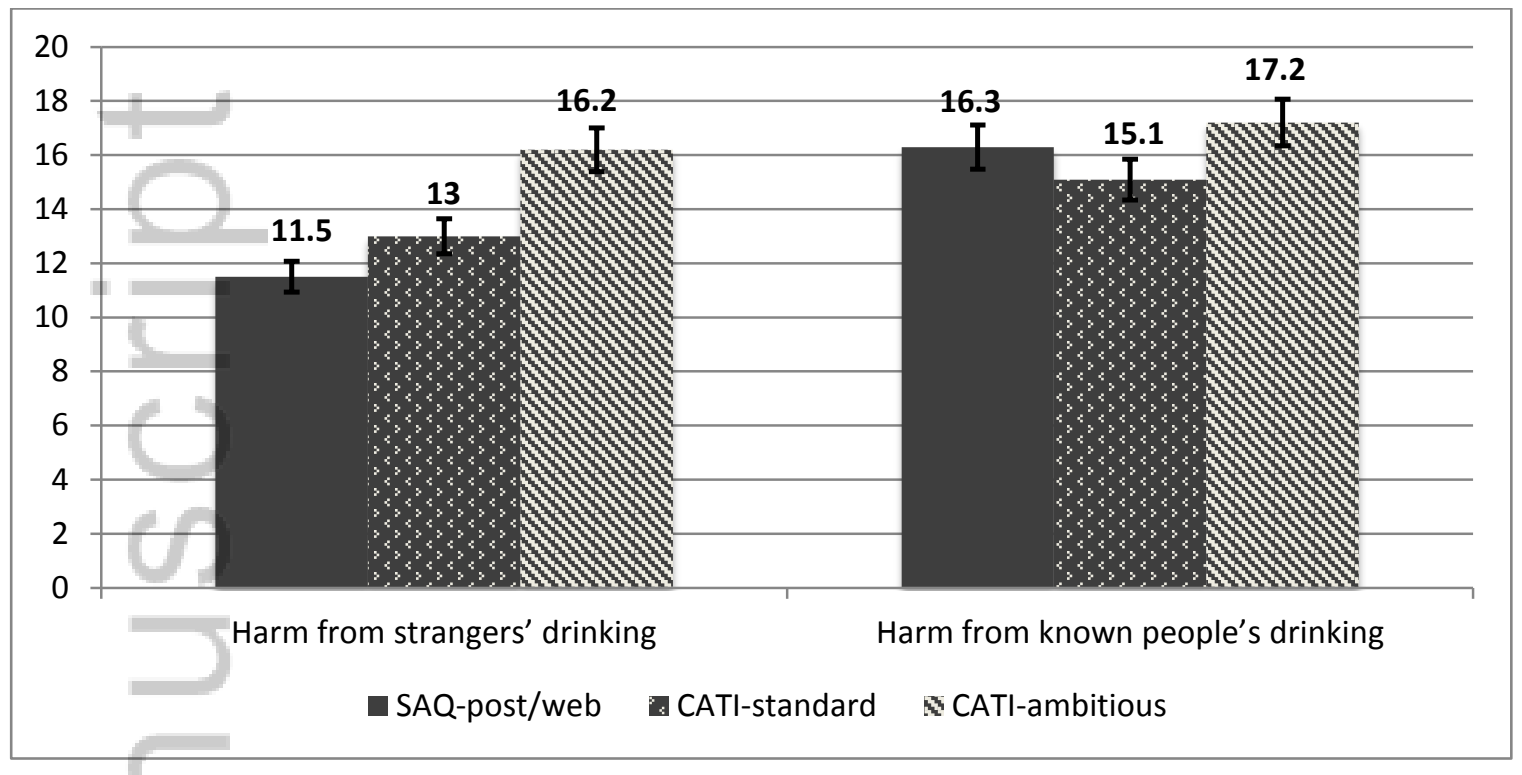

Figure 1. Proportions (\%) reporting harm from strangers' and known people's drinking during the past 12 months according to survey administration mode (weighted data).

SAQ-post/web, self-administrated combined postal and web questionnaires; CATI-standard, standardised computer-assisted telephone interviews; CATI-ambitious, computer-assisted telephone interviews with a more ambitious procedure.

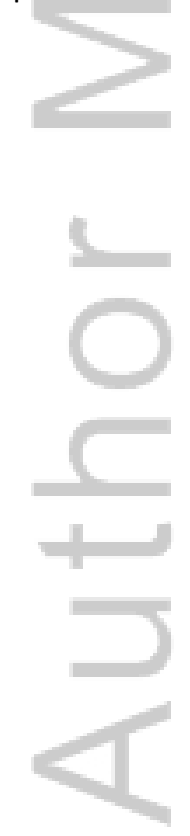

This article is protected by copyright. All rights reserved. 
Table 2. Associations between survey mode and self-reported harm from strangers' and known people's drinking (weighted data).

\begin{tabular}{|c|c|c|c|c|}
\hline \multirow[b]{2}{*}{$=1$} & \multicolumn{2}{|c|}{ Harm from strangers' drinking } & \multicolumn{2}{|c|}{ Harm from known people's drinking } \\
\hline & Unadjusted, RR (Cl) & Adjusted $^{\mathrm{a}}, \mathrm{RR}(\mathrm{Cl})$ & Unadjusted, RR (Cl) & Adjusted $^{\mathrm{a}}, \mathrm{RR}(\mathrm{Cl})$ \\
\hline \multicolumn{5}{|l|}{ Survey mode } \\
\hline SAQ-post/web (reference) & 1 & 1 & 1 & 1 \\
\hline CATI-standard & $1.15(1.00-1.33)$ & $1.28(1.10-1.48)^{* *}$ & $0.89(0.79-1.01)$ & $1.00(0.88-1.13)$ \\
\hline CATI-ambitious & $1.50(1.27-1.77)^{* * *}$ & $1.52(1.28-1.80)^{* * *}$ & $1.07(0.93-1.24)$ & $1.09(0.94-1.27)$ \\
\hline
\end{tabular}

SAQ-post/web, self-administrated combined postal and web questionnaires; CATI-standard, standardised computer-assisted telephone interviews; CATI-ambitious,

computer-assisted telephone interviews with a more ambitious procedure; RR, relative risk, $\mathrm{Cl}$, confidence interval. ${ }^{\mathrm{a}}$ Model adjusted for gender, age, Swedish origin,

education, unemployed/long-term sick leave, partner status, presence of children in the household, binge drinking frequency, contact attempts (early vs. late respondents).

$* P<0.05, * * P<0.01, * * * p<0.001$.

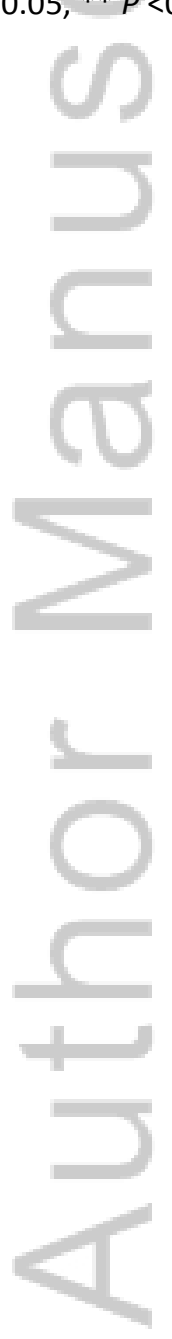

This article is protected by copyright. All rights reserved. 


\section{University Library}

\section{- M M N E R VA A gateway to Melbourne's research publications}

Minerva Access is the Institutional Repository of The University of Melbourne

Author/s:

Sundin, E;Landberg, J;Galanti, MR;Room, R;Ramstedt, M

Title:

Are differences in population prevalence of alcohol's harm to others related to survey administration mode?

Date:

2018-03-01

Citation:

Sundin, E., Landberg, J., Galanti, M. R., Room, R. \& Ramstedt, M. (2018). Are differences in population prevalence of alcohol's harm to others related to survey administration mode? DRUG AND ALCOHOL REVIEW, 37 (3), pp.375-381. https://doi.org/10.1111/dar.12550.

Persistent Link:

http://hdl.handle.net/11343/292886 